\title{
The Early Years: Beginning Early Childhood Educators' Induction Experiences and Needs in British Columbia
}

\author{
Laura K. Doan
}

Dr. Laura K. Doan is an assistant professor in the Faculty of Education and Social Work at Thompson Rivers University in Kamloops, BC, where she teaches in the Early Childhood Education Program. Laura's research interests include how to best support new early childhood educators as they enter the field of early childhood education, as well as what sustains experienced educators. Currently she is involved in the creation of a pilot induction program for new educators. Email: ldoan@tru.ca

This purpose of this study was to understand the experiences and needs of beginning early childhood educators in British Columbia. Utilizing a mixed methods approach, the research involved 114 beginning educators who took part in an online questionnaire, 11 of whom also participated in semistructured interviews. The key findings were that the work is both overwhelming and deeply satisfying; the induction support that beginning early childhood educators receive is haphazard; and beginning early childhood educators would like induction support in the form of mentoring or peer support, observations, feedback, and professional development. A model for induction support is presented.

Keywords: early childhood educators, induction, peer support, mixed methods
Every beginning early childhood educator deserves the opportunity to be adequately supported as they begin their career. Knowledge of what helps beginning educators to become successfully inducted into the profession is an important part of ensuring quality early childhood education programs for children and families. Induction refers to both the time period when an educator is first in the field, as well as specific induction activities, such as mentoring, feedback, observations, and professional development (Aitken, Ferguson, McGrath, Piggot-Irvine, \& Ritchie, 2008; Winstead Fry, 2010). It was hoped that the knowledge generated from this study would offer new insights into the needs of beginning early childhood educators, which would inform future professional development for beginning educators. Additionally, the results from this study sought to fill a gap in the literature since limited research has been carried out on the subject of novice early childhood educators' needs (Mahmood, 2012).

\section{Context}

\section{Qualifications}

Qualifications of early childhood educators vary widely internationally, nationally, and provincially, with educators receiving a certificate, diploma, or degree in early childhood education. For example, in New Zealand, early childhood educators are involved in a two- to five-year process of induction and support prior to applying for "fully registered teacher status" (Aitken et al., 2008, p. 1). Early childhood educators are partially registered prior to concluding the induction process. In Canada, where education falls under provincial jurisdiction, requirements vary from province to province. In $\mathrm{BC}$, early childhood educators apply to the Early Childhood Education Registry to be registered as an early childhood education assistant, after taking one course, or as a fully certified early childhood educator, which involves completing a recognized postsecondary early childhood education program and an additional 500 hours of work experience under the supervision of a certified early childhood educator (Friendly, Grady, Macdonald, \& Forer, 2015). Early childhood educators who have completed the educational requirements and additional work experience can apply for a five-year certificate, while those needing to complete the work experience can apply for the one-year certificate (Government of British Columbia, 2016). For the purposes of this study, all participants were certified early childhood educators who had been working in the field for five years or less.

\section{Support to Early Childhood Education Students}

Early childhood education postsecondary programs rely on "relationships between the student, the early childhood education instructor 
and the sponsor educator" (Doan, 2013, p. 21). Students are given opportunities to apply what they are learning in classes through involvement in practica in community-based early learning programs. Students take on increasing levels of program responsibility, with the support of the sponsor educator, who works alongside the student, and the instructor, who is involved in observations and the sharing of feedback (Doan, 2013). When early childhood education students graduate, the relationships change, and while instructors may encourage graduates to stay in contact for additional support (C. Alger, personal communication, March 6, 2013), barriers exist.

\section{Induction Support}

The support early childhood educators receive as they enter the profession varies too. In New Zealand, early childhood educators are assigned a mentor who is involved in providing professional development, observation, feedback, and assessments during a two- to five-year period prior to educators applying for fully registered teacher status (Aitken et al., 2008). The Kentucky teacher internship program offers a one-year mentoring program for new teachers to support them as they create their professional identities (McCormick \& Brennan, 2001). A mentoring program based in Worcester, England, is based on the premise that mentoring supports adult learning in the workplace by facilitating experiential learning (Murray, 2006). In contrast to these programs, in Canada there is no defined structure to support early childhood educators at the beginning of their careers, a time when they may possibly need it the most (Rodd, 2006). This, however, does not mean that there is not interest in supporting new educators. For example, in a report by the Early Childhood Educators of British Columbia, it was reported that "a mentoring framework is needed to help people to take steps to be mentors" (Gay, 2007, p. 18). Recognizing a shortage of mentors, the organizers of this program identified the role of a "professional critical friend" who may be a peer with the same qualifications.

\section{The Work Environment}

To understand the needs of beginning educators, it is important to identify the issues at play within the work environment. Without a formal structure for supporting beginning educators (Doan, 2014), there may or may not be adequate support to mentor them through their survival year, a term Katz (1972) used to describe an early childhood educator's first year, a time when they are simply trying to make it through the day or week. In addition, the early childhood education field is one where there is a high staff turnover, and educators may be elevated to positions of leadership when they may not be prepared (Bella \& Bloom, 2003). In BC there are 12,000 licensed early childhood educators on the ECE registry, yet only $50 \%$ of them are currently working as early childhood educators (Early Childhood Educators of British Columbia, 2011). Moreover, it is estimated that half of all early childhood educators leave the field within the first five years of work (Early Childhood Educators of British Columbia, 2012). Additionally, beginning educators may find themselves working in a child care program where they are the only staff member with recognized postsecondary credentials. A constant rotation of new staff and/or very few qualified educators can lead to role ambiguity and workplace conflict, which in turn can result in burnout (Manlove, 1993). A further area of complexity for a new educator is how one works within an environment that may be very different than their preservice experiences. For example, in 2007, the BC government produced The Early Learning Framework, a document describing the content areas for young children's learning within early learning programs (Government of British Columbia, 2007). A key piece of this document has been the introduction of pedagogical narrations, or learning stories. Though widely known in the early childhood education community within $\mathrm{BC}$ and taught within postsecondary settings, not all early childhood educators use pedagogical narrations, and this can cause tension within the workplace (Doan, 2014).

\section{The Study}

When beginning early childhood educators are not properly inducted into the profession, the quality of early childhood education programs suffers and the needs of children are not met. For example, early childhood educators may have difficulty connecting theory to practice (Rodd, 2006); they may experience exhaustion (Manlove, 1993); and some may leave the profession completely (Early Childhood Educators of British Columbia, 2012).

In this study's quantitative phase, questionnaire data were collected from 114 early childhood educators who had been working in the field for five years or less. Participants were involved in answering a series of closed and open-ended questions related to their induction experiences. In the qualitative phase of the study, 11 beginning educators took part in semistructured one-on-one interviews, with the researcher asking open-ended questions about their induction experiences and their thoughts on what beginning early childhood educators need. All interview participants also took part in the online questionnaire. The following research questions were addressed: 
1. What are beginning early childhood educators' perceptions of their induction experiences in their first year as early childhood educators?

2. What, if any, kind(s) of induction support do beginning early childhood educators receive in their first year, and how effective are these in supporting beginning early childhood educators' development of professional capacity?

3. What, if any, forms of induction or novice professional development would beginning early childhood educators like to take part in, and why?

Sample

Purposeful sampling was used to identify beginning early childhood educators within the population of newly certified educators, those who had been certified between 2008 and 2012. Purposeful sampling is where the researcher chooses participants who have experience with the phenomenon being explored (Creswell \& Plano Clark, 2007). All of the participants came from this sample, and all of the participants who were involved in semistructured interviews also completed the online survey. The selection criterion was certified early childhood educators who had been working in the early childhood education field for five years or less. In other words, this study was only open to participants who held valid early childhood education postsecondary training. It was not, for example, open to people working as assistants in early childhood programs. The researcher also used snowball sampling, a form of purposeful sampling where the researcher is involved in asking participants "to recommend other individuals to be sampled" (Creswell, 2012, p. 209). While acknowledging the use of both purposeful and snowball sampling, it is important to note that participants selected themselves to participate. The researcher did not select the participants. It is estimated that every year 800 early childhood educators are certified, so because this study involved educators who had been certified between 2008 and 2012, the population was approximately 4,000 (Government of British Columbia, 2011). However, given that half of all early childhood educators leave the field within the first five years, it was assumed the population would be much smaller, approximately 2,000 (Early Childhood Educators of British Columbia, 2012).

\section{Rationale for Selection of Participation Criterion}

The criterion for participation was selected for two reasons. First, the research questions centre around the induction experiences of beginning early childhood educators in $\mathrm{BC}$, which means educators must hold a recognized certificate or diploma from a postsecondary institution. Additionally, in order to be employed, early childhood educators must be issued a certificate to practice by the province of BC. Second, because the researcher was studying the phenomenon of induction, it was a logical step to involve those individuals who were closest to, thus most familiar with, and able to recall their initial years in the profession. The researcher chose to include educators who had been working in the field for five years or less because the induction process has been thought to take two to five years (Aitken et al., 2008).

\section{Participants in the Questionnaire}

Participants ranged in age from 18 to 60 , the mean being 31.4. There were four males and 110 females. Furthermore, all participants had completed, at the minimum, a certificate or diploma in early childhood education. Twenty-three participants had special needs postdiploma certificates; 33 had infant toddler post-diploma certificates; 16 had bachelor's degrees; and 3 had master's degrees. Participants indicated that they worked in provincially regulated child care programs. The participants represented all areas of the province: 16 from the Islands, 48 from the Vancouver Coast and Mountains, 31 from the Thompson Okanagan region, 3 from the BC Rockies, 7 from Northern BC, and 9 from the Cariboo Chilcotin Coast. Thirty-one participants were in their first year, 20 were in their second year, 24 were in their third year, 20 were in their fourth year, and 19 were in their fifth year; the mean was twenty-three months.

\section{Theoretical Framework}

The theoretical framework for this study draws on current theories of learning in professional workplaces as well as general theories of learning. Knowles, Holton, and Swanson's (2012) adult learning theory provided a theoretical context to how adults learn and, more specifically, what motivates them and how they can be taught in a way that meets their needs. The theories of professional identity development put forth by Katz (1972) and Vander Ven (1988) are pivotal to this work because the study participants are in the beginning stages of their career and are trying to develop their professional identity. Lave and Wenger's (1991) community of practice theory fits 
well given the early childhood education workplace and educational context, where educators do not receive consistent professional development and/or ongoing training. This theory provides a theoretical base from which workplace support can be considered. Teacher efficacy, which comes from Bandura's (1997) work, informs the study in a variety of ways, including in regard to why some educators remain in the profession and why others choose to leave.

\section{Professional identity development.}

Katz (1972) proposed a theoretical model for the stages of professional growth of early childhood educators. The first stage, survival, is, as its name suggests, where the educator simply tries to get through the day or week, and this stage can last up to one year. Katz wrote, "During this period the teacher needs support, understanding, encouragement, reassurance, comfort and guidance. She needs instruction in specific skills and insight into the complex causes of behaviour - all of which must be provided on the classroom site" (p. 4). What is key here is the on-site support the beginning early childhood educator requires, making it important that the mentor is physically nearby to assist the educator in daily situations, such as how to guide children's behaviour, form connections with family members, and plan programming based on children's needs and interests.

\section{Teacher efficacy.}

Self-efficacy is one part of Bandura's social cognitive theory and is related to an individual's beliefs about their own power to create change (Bandura, 1997). It is less about one's skills and more to do with what one thinks one is able to accomplish. Bandura posited the idea that "beliefs of personal efficacy constitute the key factor of human agency" (p. 3). In other words, people who believe they have the power to create change will attempt to do so. Bandura believed people are not simply products of their environments. Rather, they are seen as agents who have the power to act, based on what they believe they can do. Teacher efficacy is a term that refers to a teacher's belief in their own ability to carry out teaching tasks with success (Tschannen-Moran, Woolfolk Hoy, \& Hoy, 1998). Early childhood educators who have a strong sense of teacher efficacy are open to new ideas, are better able to plan, demonstrate greater enthusiasm for teaching, have a strong commitment to teaching, and are more likely to stay in the profession (Ozgun, 2005).

\section{Adult learning theory.}

Knowles, Holton, and Swanson (2012) believed there were inherent differences in the ways that children and adults learn, and they argued that specific principles must be considered when involved with adult learning. Theories of pedagogy and andragogy both hold assumptions on the following: the need to know; the learner's self-concept; the role of experience; readiness to learn; orientation to learning; and motivation; however, they are viewed very differently (Knowles et al., 2012). In the pedagogical model, it is assumed that learners only need to know what content they must grasp in order to pass. It is not necessary for them to know how the content can be applied to their lives. In direct contrast is the assumption from andragogy, that learners need to know why they need to learn something and that this knowledge must be shared prior to the learning process. In the theory of andragogy, emphasis is placed on the experiences of the learner (Knowles et al., 2012).

\section{Communities of practice.}

Lave and Wenger (1991) put forth the theory that learning takes place within a framework of participation, not in the mind of an individual. Lave and Wenger asserted that practitioners within communities are at work helping to bring more practitioners into the community by way of apprenticeship. From this perspective, learning occurs through hands-on participation as opposed to teaching that takes place in a classroom far removed from the workplace. Lave and Wenger's research is based on the premise that practitioners are naturally drawn to communities of practice, and their work came out of the apprenticeship experiences of tailors who became skilled master tailors through informal learning within communities of practice. Wenger and Snyder (2000) defined communities of practice as "groups of people informally bound together by shared expertise and passion for a joint enterprise" (p. 139). Wenger (1998) argued that participation in a community of practice "is essential" to learning and helps to define "what constitutes competence in a given context" (p. 229).

Communities of practice are not only for novice educators; they can benefit those with considerable experience as well (Wenger, 2000). In discussing potential benefits to organizations who use communities of practice, Wenger and Snyder (2000) reported that "communities 
of practice can drive strategy, generate new lines of business, solve problems, promote the spread of best practices, develop people's professional skills, and help companies recruit and retain talent" (p. 140). In this way, both novice and experienced educators can work together on a project that may involve the solving of various problems. Wenger and Snyder (2000) argued that communities of practice are powerful because of their ability to produce new knowledge, which helps to renew the community. However, while there seem to be many potential benefits to participation within a community of practice, there can be negative consequences as well. Communities of practice can become stagnant, resulting in a cessation of new idea creation and problem solving. Initiative, strong relationships and senses of belonging, and the ability to reflect are critical for those in communities of practice.

It is the researcher's belief that all four of the theories outlined above are relevant to the induction of new early childhood educators. Moreover, in the context of this research, each theory has the capacity to influence and inform the other. For example, a teacher's level of efficacy, how they perceive their abilities as a teacher, impacts their ability to develop their professional identity. If an early childhood educator is unable to move past Katz's (1972) survival stage, they may not develop the necessary level of teacher efficacy and may leave the profession. In addition, all four theories relate to the concept of the image of the educator. While educators are not highly valued within our society, and are thought to have low skills, Pacini-Ketchabaw, Nxumalo, Kocher, Elliot, and Sanchez (2015) argue that an educator's work is complex, involving critical reflection, a pedagogy of listening, and the coconstruction of knowledge. PaciniKetchabaw et al. (2015) look beyond the dominant images of the educator as a substitute for maternal care, an expert, and a technician and invite dialogue around the ideas of the educator in relationship and as a researcher. When looking at the image of the educator in this more complex way, one can see the need for additional support for new educators, within a context that supports the ongoing development of all educators.

\section{Method}

Mixed methods researchers believe that using both qualitative and quantitative methods will provide more comprehensive knowledge of the phenomenon under question than the use of either method alone (Given, 2008), and this is the reason mixed methods were used in this study. An online questionnaire was adapted from ones used in researching novice early childhood educators in Turkey (Ozgun, 2005) and beginning teachers in Alberta (Magill, 2002). The online questionnaire was useful because it allowed for geographic representation, while the interviews provided the opportunity to explore in detail the experiences of beginning educators. The interview schedule was modified from interview schedules used in similar research conducted by Hellsten, Prytula, and Ebanks (2009) and Swanson (1999). The data for the online questionnaire and the interviews were collected concurrently. Prior to the start of the study, the researcher ensured she had full ethical clearance from a research ethics board.

\section{Accuracy}

Several measures were undertaken to ensure validity and reliability of the study. The researcher used existing instruments from researchers who have used them with established reliability. Furthermore, the researcher conducted a pilot study to ensure that the wording of the questionnaire was understood by the participants. In addition, the coefficient alpha was used "to test for internal consistency" (Creswell, 2012 , p. 163). For each of the scales in the questionnaire, the coefficient alpha score ranged from .91 to .98. Lastly, the researcher ensured interrater reliability by involving another researcher in the initial analysis of the open-ended questions (Roberts, 2010). This was to ensure consistency. To ensure accuracy of the findings from the participants, the researcher conducted member checks by sending the interview transcripts for participants to review. Moreover, the researcher utilized peer debriefing, a process of inviting a colleague to engage in a review of the field notes and asking questions to elicit "alternative ways of looking at the data" (Bloomberg \& Volpe, 2012, p. 113).

\section{Data Analysis}

In this study, qualitative and quantitative data were analyzed in different ways. For the semistructured interviews, a process of data condensation through the use of codes (Miles, Huberman, \& Saldana, 2014) was used. Prior to the start of data collection, provisional codes were assigned using the research questions, conceptual framework, and codes and themes used in similar research studies on beginning early childhood educators (Miles et al., 2014). This phase of coding was meant as a starting point only, and the researcher remained open to further codes that emerged from the data, something that is consistent with this form of coding (Miles et al., 2014). Second-level coding began with additional codes emerging. 
The online questionnaire included mostly quantitative data with several open-ended response questions as part of the mixed-methods approach. The open-ended questions were analyzed in the same way as the interview data. Using SPSS software, the researcher analyzed the Likert-scale questions under each cluster to determine the areas in which beginning early childhood educators require and receive the most support. The findings from both data sets were then further analyzed to understand what is important and what can be learned (Bloomberg \& Volpe, 2012). This analysis included a process of iterative thematic coding that involved a three-step nonlinear process of looking at individual findings to determine their meaning, viewing all of the findings to see connections, and searching for similarities and differences among individual participants. Out of this process, key themes emerged, as outlined below.

\section{Limitations}

There are at least four possible limitations of this study. First, Aitken et al. (2008) reported an "inability to use observation as a means of gathering data" as a possible limitation, and this limitation may be relevant to this study because the researcher relied on participant reports and not direct observations. Second, the quantitative data gathered through the use of an online questionnaire may be biased due to the fact that participants took part through a self-selection process. For example, it is probable that those who took part were either beginning early childhood educators who were doing quite well in their first year or were doing rather poorly. Third, the data from the semistructured interviews may not be fully accurate because it is possible that what participants shared is different from what they do in practice. In addition, interview participants were recalling what their experiences had been in their first year as an educator, and their memories may not be exact. Fourth, relative to the number of beginning early childhood educators in BC, this study involved a small number. Thus, the findings, though useful for this particular context, are not generalizable.

\section{Key Themes}

\section{The Work is Both Overwhelming and Deeply Satisfying}

In seeking to answer the first research question (What are beginning early childhood educators' perceptions of their induction experiences in their first year as early childhood educators?), the main theme that emerged from the analysis of the data, both the online questionnaires and the interviews, is that beginning early childhood educators find the work to be both overwhelming and deeply satisfying. In the online questionnaire, $34 \%$ of beginning early childhood educators reported that they did not get the support they needed with regard to a workload that reflected their training and lack of experience. What is meant by workload is that the child-to-educator ratio is the same for both new and experienced educators. Because the job title is the same, there is no difference in what is expected of new educators in terms of number of hours worked and task completion. For example, one interview participant described his second day on the job, when he was expected to do everything that the experienced staff did, including opening up the centre, when he still did not know the children or the families. Further to this finding, $49 \%$ of the online questionnaire participants reported receiving no or little support in this area. In this study, 34\% reported receiving no support in understanding the philosophy of the program. One interview participant described her experiences as "sink or swim" in a workplace where the program philosophy was very different than what she was used to.

Despite the overwhelming workload reported by beginning early childhood educators in this study, a large majority ( $89 \%)$ of participants who completed the online questionnaire reported deriving high levels of satisfaction from their work as an early childhood educator. Additionally, $68 \%$ of these new early childhood educators in BC agreed or strongly agreed that they would choose to go into the field of early childhood education again.

\section{The Induction Support Beginning Early Childhood Educators in BC Receive is Haphazard}

In analyzing the findings related to the second research question (What, if any, kind(s) of induction support do beginning early childhood educators receive in their first year, and how effective are these in supporting beginning early childhood educators' development of professional capacity?), what became clear is that the induction support beginning early childhood educators in BC receive is haphazard, meaning that it is inconsistent. Based on the findings from this study, beginning early childhood educators in BC cannot assume they will receive the induction support they need in their first year. Results showed that support was very much dependent on the particular job site, the educators on site, and the level of staff turnover. In the online questionnaire, between $43 \%$ and $52 \%$ of participants indicated they received no or little support through such practices as feedback, mentoring, observations, professional development, and other induction activities. Feedback was the area in which the highest level of participants reported receiving no or little support. 
In regard to supervisory practices, $52 \%$ to $56 \%$ of beginning early childhood educators who took part in the online questionnaire reported that they received no or little support from supervisors. Thirty-two percent of beginning early childhood educators reported receiving no visit for evaluation, and $22 \%$ reported receiving little in this area. Twenty-four percent of beginning early childhood educators reported receiving nothing regarding one-on-one discussions with their primary supervisor to address their goals, concerns, and difficulties. Interview participants were asked if they felt they had received the support they needed in their first year of work, and most (64\%) revealed that they had not received the support they required.

Beginning Early Childhood Educators in BC Would Like Induction Support in the Form of Mentoring or Peer Support, Observations, Feedback, and Professional Development

In identifying the key theme for research question 3 (What, if any, forms of induction or novice professional development would beginning early childhood educators like to take part in, and why?), it was determined that beginning early childhood educators in $\mathrm{BC}$ would like induction support in the forms of mentoring or peer support, observations, feedback, and professional development. The participants who identified themselves as having taken part in some or all of the above induction activities spoke highly of the experiences, emphasizing the importance of these kinds of experiences in their initial year as an early childhood educator. Some participants had not received the induction support they needed, and this was due to several factors, including a lack of supervisory visits to the classroom, little or no time to discuss programming and/or individual concerns, and a lack of support to help them cope with feelings of frustration and/or inadequacy. Furthermore, beginning early childhood educators in the study needed additional support in knowing how to deal with the low respect given to those who work with very young children. While many beginning early childhood educators in $\mathrm{BC}$ form connections with and receive support from a colleague at work, educators in this study did not get the support they needed with regard to the lack of correspondence between theory and practice.

\section{Practical and Theoretical Implications}

From the three major findings, a major implication that addresses all three of the research questions is that the early childhood education workplace is ideally suited for new educators to be successfully inducted into the profession and to form their professional identity (Flores \& Day, 2006). This idea fits very well with the communities of practice theory put forth by Lave and Wenger (1991), where learning is viewed as something that occurs through participation, not solely in the mind of an individual. Despite the fact that it was not consistent for all beginning early childhood educators, $41 \%$ of beginning educators in this study reported receiving great or very great support with regards to forming a connection with an experienced educator; $35 \%$ reported receiving great or very great support in feeling comfortable interacting with all staff; and $29 \%$ reported receiving great or very great opportunities to observe educators. Beginning educators in this study reported that they receive support from colleagues. There is a baseline on which to build. Beginning educators working alongside experienced educators can gain perspective on who they are and what their identity is as an early childhood educator.

\section{Model of Practice for the Induction of Beginning Early Childhood Educators}

The model of practice for the induction of beginning early childhood educators presented below is based on the positive finding from this research that beginning educators who do receive support do so from their workplace and/or the greater early childhood education community. The model is future oriented and implies that change is needed in order to move to a system where all beginning educators are supported. In this model (see Figure 1), beginning educators are positioned in the first circle, representing their importance and the significance of the support they should receive. Beginning educators who participated in this study indicated that the work was both overwhelming and deeply satisfying. Furthermore, participants wanted a program of support for beginning early childhood educators. The participants who did receive induction support did so in the workplace from fellow educators, supervisors, or administrators. Additionally, participants received support from the greater early childhood education community, such as postsecondary faculty, licensing officers, and educators from other child care centres. Early childhood educators in this study who did not receive adequate support believed they were perceived in one or more of the following ways: as an empty vessel, knowing nothing; as someone who is licensed and ready to go; as one who needs to learn how things are done in the real world; or as one who needs nothing. 


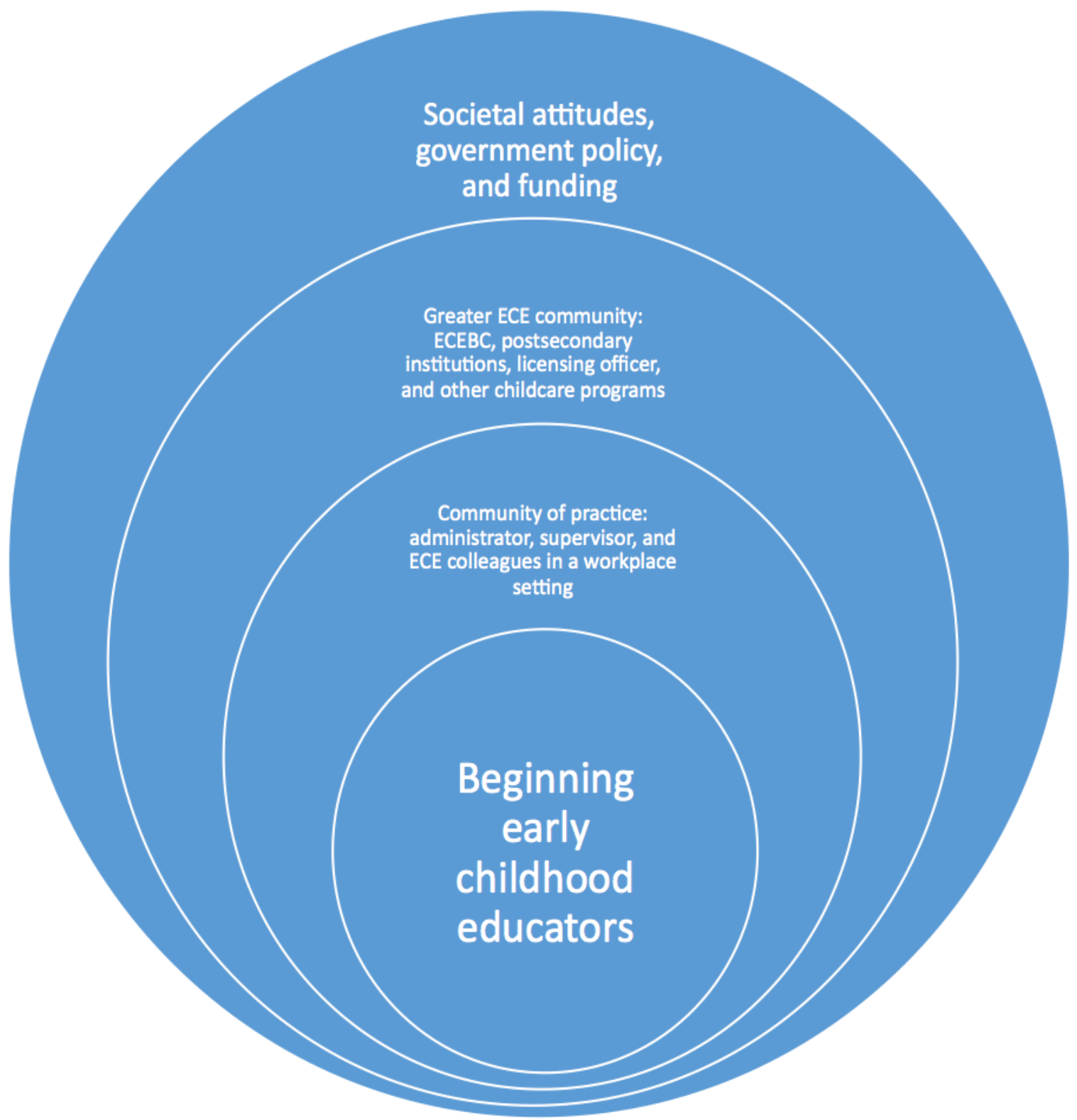

Figure 1: A model for the induction of beginning early childhood educators.

Perceptions of new early childhood educators.

Some beginning educators in BC are left on their own, without adequate induction support during their first year of work. It is as if they are viewed as fully prepared, or "licensed and ready to go," when in fact educators in this study reported that they did not want to be left on their own. The concept of being "licensed and ready to go" is linked to the idea that the beginning educator needs nothing. It may come from a view that educators have already received what they need through their postsecondary training and now need to get on with the work of performing as an educator. In addition, some early childhood educators in $\mathrm{BC}$ feel undervalued by their coworkers. Attempts to bring new programming ideas into the classroom that had been learned in the educator's recent education were rebuffed, and due to an environment where those with seniority held the power, the new educator felt "shut down." This finding ties in well with the idea that the new educator needs to learn how things are done in the real world. Furthermore, some beginning educators think they are viewed as empty vessels, knowing nothing. This is a way of looking at beginning educators as not having anything to add. It is the antithesis of viewing the early childhood educator as being a team player, ready to help and add to the workplace environment. Despite 
their novice status, beginning educators are not empty vessels, ready to be filled. Rather, they are ready and willing to contribute to the learning environment.

\section{How new early childhood educators would like to be treated.}

The beginning educators in this study indicated that they would like to be valued, shown an interest in, given feedback, included on the team, and invited to professional development opportunities. Beginning educators want to be valued by their coworkers and supervisors. Participants who felt valued described situations where experienced educators collaborated with them by sharing programming ideas and by asking for their thoughts and ideas. Furthermore, beginning educators want coworkers and supervisors to take an interest in them. This may include intentional communication with the beginning educator regarding how their induction is going. Whatever form it takes, this requires someone in the workplace who cares and takes the time to show the beginning educator that they are interested in them. In addition, beginning educators want feedback. Performance feedback is a regular occurrence for early childhood education students, and educators in this study wanted feedback in the form of reviews of their practice to help them in knowing how they were doing in their new role. This feedback could take several forms, including informal verbal feedback throughout the day and formal employee evaluations.

Beginning educators in this study want to be included on the team and they want to be invited to professional development opportunities. The majority of beginning educators in this study are not working alone in an educational setting. Most beginning educators are joined by one to three colleagues in their workplaces. The concept of a team is something that is taught and put into practice in postsecondary early childhood education preparation programs, but what happens in the workplace can be very different. Some beginning educators do not experience a feeling of being part of a team. In some cases, beginning educators find themselves in work environments where there is a definite hierarchy and chain of command that allows for little in the way of innovation or new ideas from beginning educators. This is in direct contrast to what beginning educators in this study indicated they want, which is to be active, contributing members of teams in the workplace. This includes opportunities for professional development, such as paid time off to attend professional development as well as monetary support to cover the associated costs. Beginning educators are in a place in their career where they need to have opportunities to gain information that affects their practice. Additionally, beginning educators need professional development for the purpose of meeting other educators in the community.

In this model, which is described using present tense, the beginning early childhood educator is surrounded by a community of practice that includes supportive colleagues who are able to engage in mentoring and/or peer support. Support is context specific, not "cookie cutter." Every early childhood centre is unique, staff groups have different strengths and challenges, and new educators have different needs and abilities. Therefore, this is not a "one-size-fits-all" approach. The induction support is consistently offered, but it is based on the context of the specific community of practice and the individual needs of the beginning early childhood educator. This model is not based on the underlying assumptions that new early childhood educators know nothing, need nothing, need to learn how things are done in the "real world," and are licensed and ready to go. Rather, beginning educators are viewed as ready to begin their work as a contributing member of the workplace team. The idea of developing communities of practice is not a new one, and in BC, the Community Early Learning and Child Care Facilitators Pilot Project, which came out of the Investigating Quality Project, involves learning circles, critical reflection, and learning how to do innovative work (Mirau, 2015). The learning circles were forums where educators had opportunities to "share their established and emerging practices" (Unit for Early Years Research and Development, n.d., p. 6). Though the purpose of the facilitators project is not specifically directed at beginning educators, it is assumed that both new and experienced educators will benefit. Projects like these challenge the traditional discourse of training and delivery, where educators are viewed as passive vessels waiting to be filled (Pacini-Ketchabaw et al., 2015). Rather, the educator is seen as an active, contributing agent, participating in the coconstruction of knowledge. Furthermore, this perspective on continued learning within a community of practice supports the image of the educator as being "in process" (Pacini-Ketchabaw et al., 2015, p. 64), which challenges the current notions of professionalization and competencies.

Using the workplace as the learning environment for new educators aligns well with the theory of adult learning, which places importance on the experiences of the learner (Knowles et al., 2012). In this kind of model, both novice and more experienced educators can benefit. Though it is a theory based on children's learning, Vygotsky's zones of proximal development (1986) seem to fit well within the context of workplace support and/or learning. Perhaps it is because educators are being supported in their moment of need -in that place of what they know and what they need to know. This concept of readiness to learn, from the theory of adult learning, is critical for those involved in supporting new educators. Knowles et al. (2012) asserted that adults "become ready to learn when their life situation creates a need to know" (p. 192). They went on to suggest that the more "adult learning professionals can anticipate and understand adults' life situations 
and readiness for learning, the more effective they can be" (pp. 192-193). Here it would seem that the team-centred approach that is common in most early childhood settings is poised to support new educators as they learn, through their zone of proximal development, when they are ready to learn. Lave and Wenger (1991) wrote this about identities: "We conceive of identities as long-term, living relations between persons and their place and participation in communities of practice. Thus identity, knowing, and social membership entail one another" (p. 53). This study's findings indicate that a significant number of beginning educators are in workplaces that do not operate under the idea of communities of practice. These are workplaces where beginning educators are left on their own to figure things out, instead of having the potential benefit of learning alongside experienced educators for the purpose of forming a professional identity. This type of environment contrasts with the ideas put forth by Sachs (2000), who reported that networks based on mutual trust can develop into ongoing learning communities where learning occurs for everyone involved.

In this induction model, communication is pivotal. Supportive administrative and supervisory practices are enabled, which allows time for the beginning educator to observe more experienced educators. Furthermore, the beginning educator is able to receive ongoing, relevant feedback on their practice. There is both time for planning with colleagues and summative evaluations, which allow the beginning educator to grow and fully develop into a professional. The entire staff team, including the beginning educator, has the opportunity for regular, sustained professional development, which of course is helped by funding and support by the government. The early childhood community of practice is deeply connected with both the local and provincial organization representing early childhood educators. Additionally, there are significant connections with the local early childhood education program at the nearest postsecondary institution, which assists the staff in remaining current. While additional funding from the provincial and federal governments would be helpful, this model can be put into place without it, with an aim to testing the model.

\section{Conclusion}

The findings from this study indicate that beginning early childhood educators in $\mathrm{BC}$ have both a need and a desire for induction support in the form of mentoring or peer support, observations, feedback, and professional development. A model for the induction of beginning educators suggests a move toward viewing early childhood education workplaces as communities of practice, a term used by Lave and Wenger (1991) and seen in the Investigating Quality Project (Unit for Early Years Research and Development, n.d.). To bring this concept into fruition, much will be required, including the involvement of governments, postsecondary institutions, and provincial ECE organizations. Despite challenges such as inconsistent induction support, beginning early childhood educators in BC are deeply satisfied with their work, and this is reason for optimism.

\section{References}

Aitken, H., Ferguson, P. B., McGrath, F., Piggot-Irvine, E., \& Ritchie, J. (2008). Learning to teach: Success case studies of teacher induction in Aotearoa. Wellington, New Zealand: New Zealand Teachers Council.

Bandura, A. (1997). Self-efficacy: The exercise of control. New York, NY: W. H. Freeman \& Company.

Bella, J., \& Bloom, P. J. (2003). Zoom: The impact of early childhood leadership training on role perceptions, job performance, and career decisions. Wheeling, IL: The Centre for Early Childhood Leadership.

Bloomberg, L. D., \& Volpe, M. (2012). Completing your qualitative dissertation: A road map from beginning to end. Thousand Oaks, CA: SAGE.

Creswell, J. W. (2012). Educational research: Planning, conducting, and evaluating quantitative and qualitative research (4 ${ }^{\text {th }}$ ed). Boston, MA: Pearson Education.

Creswell, J. W. \& Plano Clark, V. L. (2007). Designing and conducting mixed methods research. Thousand Oaks, CA: SAGE.

Doan, L. K. (2013). Mentoring: A strategy to support novice early childhood educators. Canadian Children, 38(2), 21-24. 
Doan, L. K. (2014). The early years: An exploration of the experiences and needs of novice early childhood educators in British Columbia (Doctoral dissertation). Retrieved from: http://theses.ucalgary.ca/bitstream/11023/1606/2/ucalgary_2014_Doan_Laura.pdf

Early Childhood Educators of British Columbia. (2011). By the numbers: BC children, families, and child care [pamphlet]. Retrieved from: http://www.cccabc.bc.ca/plan/wp-content/uploads/2011/12/CCCABC_ECEBC_Factsheet3.pdf

Early Childhood Educators of British Columbia. (2012). May 2012 is child care month: Early childhood educators matter to BC's economy [media release]. Retrieved from: http://www.ecebc.ca/news/ECEBC_ChildCareMonth_2012.pdf

Flores, M. A. \& Day, C. (2006). Contexts which shape and reshape new teachers' identities: A multi-perspective study. Teaching and Teacher Education, 22, 219-232.

Friendly, M., Grady, B., Macdonald, L., \& Forer, B. (2015). Early childhood education and care in Canada: 2014. Toronto, ON: Childcare Resource and Research Unit.

Gay, C. (2007). Developing a strategy for professional leaders. Early Childhood Educators of British Columbia strategy session. Retrieved from: http:/www.ecebc.ca/leadership/files/ECEBC_Strategy_Session.pdf

Given, L. M. (2008). The SAGE encyclopedia of qualitative research methods. Los Angeles, CA: SAGE.

Government of British Columbia. (2007). British Columbia early learning framework. Victoria, BC: Ministry of Education; Ministry of Health; Ministry of Children and Family Development; Early Learning Advisory Group.

Government of British Columbia. (2011). ECE statistics and information. Ministry of Children and Family Development. Retrieved from: http://www.mcf.gov.bc.ca/childcare/ece/stats.htm

Government of British Columbia. (2016). Five year early childhood educator (5yr ECE) certification requirements. Ministry of Children and Family Development. Retrieved from: http://www.mcf.gov.bc.ca/childcare/ece/ecea_5_year.htm

Hellsten, L. M., Prytula, M. P., \& Ebanks, A. (2009). Teacher induction: Exploring beginning teacher mentorship. Canadian Journal of Education, 32(4), 703-733.

Katz, L. (1972). Developmental stages of preschool teachers. Urbana, IL: Educational Resources Information Centre Clearinghouse on Early Childhood Education.

Knowles, M. S., Holton, E. F., \& Swanson, R. A. (2012). The adult learner: The definitive classic in adult education and human resource development. Abingdon, England: Routledge.

Lave, J., \& Wenger, E. (1991). Situated learning: Legitimate peripheral participation. New York, NY: Cambridge University Press.

Magill, A. L. (2002). Studying the needs and experiences of beginning teachers (Unpublished master's thesis). University of Alberta, Edmonton, Canada.

Mahmood, S. (2012). "Reality shock": New early childhood education teachers. Journal of Early Childhood Teacher Education, 34, 154-170.

Manlove, E. E. (1993). Multiple correlates of burnout in child care workers. Early Childhood Research Quarterly, 8(4), 499-518.

McCormick, K. M. \& Brennan, S. (2001). Mentoring the new professional in interdisciplinary early childhood education: The Kentucky teacher internship program. Topics in Early Childhood Special Education, 2001(21), 131-149.

Miles, M. B., Huberman, A. M., \& Saldana, J. (2014). Qualitative data analysis: A methods sourcebook (3 ${ }^{\text {rd }}$ ed.). Thousand Oaks, CA: SAGE. 
Mirau, E. (2015). Mentoring for early childhood educators: A report for the Ministry of Children and Family Development (Unpublished master of education report). University of Victoria, Canada.

Murray, J. (2006). Designing and implementing a mentoring scheme: University of Worcester surestart-recognized sector-endorsed foundation degree in early years. In A. Robins (Ed.), Mentoring in the early years (pp. 63-78). London, England: Paul Chapman.

Ozgun, O. (2005). The relationship of novice Turkish early childhood education teachers' professional needs, experiences, efficacy beliefs, school climate for promoting early childhood learning, and job satisfaction (Unpublished doctoral dissertation). Syracuse University, New York.

Pacini-Ketchabaw, V., Nxumalo, F., Kocher, L., Elliot, E., \& Sanchez, A. (2015). Journeys: Reconceptualizing early childhood practices through pedagogical narration. Toronto, ON: University of Toronto Press.

Roberts, C. M. (2010). The dissertation journey: A practical and comprehensive guide to planning, writing, and defending your dissertation. Thousand Oaks, CA: Corwin.

Rodd, J. (2006). Leadership in early childhood (3 ${ }^{\text {rd }}$ ed.). New York, NY: Open University Press.

Sachs, J. (2000). The activist professional. Journal of Educational Change 1, 77-95.

Swanson, M. (1999). First year teacher induction (Unpublished doctoral dissertation). University of Alberta, Edmonton, Canada.

Tschannen-Moran, M., Woolfolk Hoy, A., \& Hoy, W. K. (1998). Teacher efficacy: Its meaning and measure. Review of Educational Research, 68, 202-248.

Unit for Early Years Research and Development. (n.d.). Investigating quality project. Retrieved from: http://www.web.uvic.ca/ eyrd/ images/pdfs/iqproject.pdf

Vander Ven, K. (1988). Pathways to professional effectiveness for early childhood educators. In B. Spodek, O. Saracho, \& D. Peters (Eds.) Professionalism and the early childhood practitioner (pp. 137-160). New York, NY: Teachers College Press.

Vygotsky, L. (1986). Thought and language. Cambridge, MA: Massachusetts Institute of Technology.

Wenger, E. (1998). Communities of practice: Learning, meaning, and identity. New York, NY: Cambridge University Press.

Wenger, E. (2000). Communities of practice and social learning systems. Organization, 7(2), 225-246.

Wenger, E. C. \& Snyder, W. M. (2000). Communities of practice: The organizational frontier. Harvard Business Review, 78(1), $139-146$.

Winstead Fry, S. (2010). The analysis of an unsuccessful novice teacher's induction experiences: A case study presented through layered account. The Qualitative Report, 15(5), 1164-1190. 